This paper is published in the open archive of Mid Sweden University DIVA http://miun.diva-portal.org with permission of the publisher

Citation for the peer-reviewed published paper:

Walter K, Paulsson M, Wackerberg E. Energy efficient refining of Black spruce TMP by using acid hydrogen peroxide : Part 2. Washing, chelating and bleaching studies. Stockholm: SPCI; Nordic Pulp \& Paper Research Journal. 2009;24(3):266-272.

URL to article at publishers site:

http://dx.doi.org/10.3183/NPPRJ-2009-24-03-p266-272 


\section{Energy efficient refining of black spruce TMP by using acid hydrogen peroxide: Part 2. Washing, chelating and bleaching studies}

Karin Walter and Magnus Paulsson, Eka Chemicals AB, Bohus, Sweden, and Mid Sweden University, Sundsvall, Sweden, Eva Wackerberg, Eka Chemicals AB, Bohus, Sweden

KEYWORDS: TMP, Black spruce, Energy reduction, Bleaching, Hydrogen peroxide, Sodium dithionite, Brightness, Metals

SUMMARY: The acid hydrogen peroxide system has the potential to significantly reduce the specific energy consumption in the production of softwood thermomechanical pulps (TMPs). A drawback of the chemical system is discoloration of the pulp during refining. The work presented in this study evaluates the possibility to regain the lost brightness by washing, chelating and sodium dithionite or hydrogen peroxide bleaching of the treated pulps.

A washing or chelating procedure can reduce the metal ion content of the chemically treated TMPs considerably, though brightness can be increased by a maximum of two ISO units. The amount of iron can be further reduced to a level similar to that of untreated pulps by performing a reducing agent-assisted chelating stage $\left(\mathrm{Q}_{\mathrm{Y}}\right)$ with dithionite. The discoloration cannot, however, be completely eliminated. The brightness decrease of the treated pulps is thus not only caused by higher iron content in the pulp, but is also dependent on the type of iron compound and/or other coloured compounds connected with the acid hydrogen peroxide treatment.

Oxidative bleaching with hydrogen peroxide $(\mathrm{P})$ is more effective than reductive bleaching with sodium dithionite in regaining the brightness lost during the energy reductive treatment. By using a $\mathrm{Q}_{\mathrm{Y}} \mathrm{P}$ sequence, a hydrogen peroxide charge of $3.8 \%$ was needed to reach an ISO brightness of $75 \%$ for the chemically treated pulps. The corresponding hydrogen peroxide charge for the untreated TMP reference was $2.5 \%$.

\section{ADDRESSES OF THE AUTHORS: Karin Walter \\ (karin.walter@akzonobel.com), Magnus Paulsson (magnus.paulsson@akzonobel.com): Eka Chemicals AB, SE-445 80 Bohus, Sweden, and Mid Sweden University, FSCN, SE-851 70 Sundsvall, Sweden. \\ Eva Wackerberg (eva.wackerberg@akzonobel.com): Eka Chemicals AB, SE-445 80 Bohus, Sweden. Corresponding author: Karin Walter}

In a time when global wood and energy prices are rising, efficient processes for producing and utilizing pulp and paper products are of great importance. Mechanical and chemimechanical pulping make efficient use of available virgin fibre resources since they are high-yield manufacturing processes. However, the mechanical pulping process is electrical energy intensive and for thermomechanical pulp (TMP) the specific energy consumption can be up to 3-3.5 MWh per ton of pulp (Jackson, Wild 1999; Ali (Viforr), Salmen 2005; Francis et al. 2006; Viljakainen 2006). Several of the proposed methods for reducing energy consumption during the production of high-yield pulps influence the optical properties unfavourably. Examples of such treatments are biomechanical pulping using whiterot fungi (Akamatsu et al. 1984; Setliff et al. 1990; Akhtar et al. 1993; Akhtar et al. 1998; Agarwal, Akhtar 2000) or treatments where higher temperatures are used to soften the material before and during refining (Höglund et al. 1997; Norgren et al. 2004). To ensure profitability in the industry, it is thus essential to develop innovative solutions that substantially reduce energy consumption while maintaining pulp quality.

The optical properties of high-yield pulps are quality parameters that are becoming increasingly important (Ohlsson, Federer 2002; Luoma et al. 2004) since the brightness and whiteness requirements for improved newsprint and many uncoated and coated magazine paper grades (e.g., SC, LWC, MWC) have been raised in recent years. Furthermore, the brightness stability of these lignin-containing pulps is poor and, for some wood raw materials and pulping processes, this characteristic together with low maximum obtainable brightness (whiteness) level also pose major obstacles for using mechanical and chemimechanical pulps in long-life, highquality papers. Consequently, it is important that the optical properties do not deteriorate substantially or that the brightness/whiteness can be cost-effectively restored during a subsequent bleaching stage when introducing treatments aimed at reducing the required refining energy.

An inter-stage treatment with acid hydrogen peroxide can reduce energy consumption during the production of softwood TMP (Walter et al. 2009). The reduction in refining energy can be obtained without any substantial change in fibre length, fractional composition of the pulp or tensile strength of the paper. One hypothesis is that the radicals formed when hydrogen peroxide decomposes under acid conditions attack the carbohydrate-rich outer fibre surfaces of high-freeness pulps and weaken these cell wall layers. The fibre development is thereby facilitated and the energy needed to attain a particular degree of pulp refinement is reduced. The chemical system consists of hydrogen peroxide, an activator such as ferrous sulphate and, optionally, an enhancer, e.g., ethylenediaminetetraacetic acid. At present, one drawback of the acid hydrogen peroxide system is the discoloration associated with the chemical treatment. Obvious reasons for the discolouring of the pulp when using a ferrous iron activator are the precipitation of iron salts when the $\mathrm{pH}$ is raised and the formation of ferric iron during the course of the reaction. The formation of coloured ferric complexes with wood constituents is another plausible explanation, since it is well known that many lignin-metal and extrac- 
tive-metal complexes are highly coloured (Janson, Forsskåhl 1989; Ni et al. 1997; Ni et al. 1998a; Ni et al. 1999; Peart, Ni 2001). The oxidation may also generate new lignocellulosic structures that directly or indirectly (together with metal ions) contribute to the observed discoloration.

The present study, which is a continuation of previous work (Walter et al. 2009), describes the bleachability under oxidative and reductive conditions of untreated and acid hydrogen peroxide-treated Black spruce (Picea mariana) TMPs. Different approaches to lowering the iron content of the pulps before bleaching and their effect on brightness and bleachability are discussed.

\section{Experimental}

\section{Materials}

Thermomechanical pulps (TMPs) made from Black spruce (Picea mariana) with a freeness of about $100 \mathrm{ml}$ CSF, produced at Andritz pilot plant facility in Springfield, $\mathrm{OH}$, USA, were used in the present study. The pulps were centrifuged to a dry content between 35 and $38 \%$ and stored in a freezer before further treatments. More information about the pulps is presented in Table 1 and elsewhere (Walter et al. 2009).

The hydrogen peroxide $\left(\mathrm{H}_{2} \mathrm{O}_{2}, 59 \%\right)$ used in the bleaching studies was obtained from Eka Chemicals AB, Bohus, Sweden. The sodium silicate (Apsil DS 220, with a weight ratio between $\mathrm{SiO}_{2}$ and $\mathrm{Na}_{2} \mathrm{O}$ of $1: 2.25$ ) was supplied by $\mathrm{PQ}$ Europe, Amersfoort, Netherlands. The sodium dithionite $\left(\mathrm{Na}_{2} \mathrm{~S}_{2} \mathrm{O}_{4} \times \mathrm{H}_{2} \mathrm{O},>85 \%\right)$ used in the bleaching studies was supplied by Alfa Aesar, Lancashire, England, and the sodium dithionite $\left(\mathrm{Na}_{2} \mathrm{~S}_{2} \mathrm{O}_{2}, \times 2 \mathrm{H}_{2} \mathrm{O}\right.$, $>85 \%$ ) used in the chelating studies was supplied by Fisher Scientific, Västra Frölunda, Sweden. The diethylenetriaminepentaacetic acid, sodium salt $\left(\mathrm{Na}_{5} \mathrm{DTPA}, 40 \%\right)$ and ethylenediaminetetraacetic acid, sodium salt $\left(\mathrm{Na}_{4}\right.$ EDTA, $\left.40 \%\right)$ used in the bleaching studies were from Akzo Nobel Functional Chemicals, Amersfoort, Netherlands. Sulphuric acid $\left(\mathrm{H}_{2} \mathrm{SO}_{4}\right)$ from Fluka, Seelze, Germany, and sodium hydroxide $(\mathrm{NaOH})$ from Scharlau, Sentmenat, Spain, were used for $\mathrm{pH}$ adjustment.

\section{Washing and chelating}

Pulp washing experiments, using deionised water where the $\mathrm{pH}$ was unadjusted or adjusted with $1 \% \mathrm{H}_{2} \mathrm{SO}_{4}(\mathrm{pH}$ 2.3 ), were performed to determine the reduction in metal ion content and the effect on pulp brightness. The washing experiments without $\mathrm{pH}$ adjustment (W) were carried out at $70^{\circ} \mathrm{C}$ with $15 \mathrm{~g}$ of (bone dry) pulp. The pulp was suspended in $900 \mathrm{ml}$ of deionised water for 30 seconds and then dewatered to about $25 \%$ and the filtrate re-circulated once to avoid losses of fibres and fines material. The procedure was repeated once and the two filtrates were combined and used for determining the chemical oxygen demand (COD) according to the procedure described below. The acidic pulp wash $\left(\mathrm{W}_{\mathrm{A}}\right)$ was performed according to the conditions employed for the chelating stage as described below with the exception that the pulp was dewatered to approximately $25 \%$ before pulp analyses.

A chelating (Q) stage was carried out in order to reduce the metal content of the pulps prior to oxidative bleaching with hydrogen peroxide $(\mathrm{P})$ or reductive bleaching with sodium dithionite (Y). The pulps were treated with $0.2 \%$ (except for trial series HP-D which was treated with $0.4 \%$ ) $\mathrm{Na}_{5} \mathrm{DTPA}$ at $50^{\circ} \mathrm{C}$ and $4 \%$ pulp consistency. After a retention time of 30 minutes, the pulp was dewatered and the filtrate re-circulated once to avoid losses of fibres and fines material. The pulp was then centrifuged to a pulp dryness of approximately $40 \%$. The metal ion content of the pulp and the COD and $\mathrm{pH}$ of the effluent were determined as described below. A $\mathrm{pH}$ optimization of the $\mathrm{Q}$ stage showed that the $\mathrm{pH}$ should be between 6.0 and 6.5 to reach both low iron and manganese levels. The desired $\mathrm{pH}$ was obtained by adding $0-0.7 \%$ sodium hydroxide to the chelating stage.

A reducing agent-assisted chelating $\left(Q_{Y}\right)$ stage was performed in an attempt to further reduce the metal content of the pulps prior to oxidative bleaching with hydrogen peroxide. $\mathrm{Na}_{2} \mathrm{~S}_{2} \mathrm{O}_{4}, 0.5 \%$, and $\mathrm{Na}_{5} \mathrm{DTPA}, 0.2 \%$, was added to the chelating stage. The $\mathrm{pH}$ was optimized to about 6 by adding $0.1-0.5 \%$ sodium hydroxide. The procedure followed the above description for a chelating stage with the exception that the pulp was dewatered to approximately $50 \%$ before pulp analyses. The $\mathrm{H}_{2} \mathrm{SO}_{4}$, $\mathrm{NaOH}, \mathrm{Na}_{4}$ EDTA and $\mathrm{Na}_{5}$ DTPA addition levels are given as $100 \%$ active component calculated on bone dry pulp.

\section{Dithionite bleaching}

Medium consistency dithionite $\left(\mathrm{Na}_{2} \mathrm{~S}_{2} \mathrm{O}_{4}\right)$ bleaching was performed at a pulp consistency of $8 \%$ in plastic bags at a temperature of $60^{\circ} \mathrm{C}$ using $1 \% \mathrm{Na}_{2} \mathrm{~S}_{2} \mathrm{O}_{4}$. After a retention time of 45 minutes, the pulp was dewatered and the filtrate re-circulated once to avoid losses of fibres and fines material. The filtrate was collected and used to determine $\mathrm{pH}$ and COD values according to the procedures described below. The bleached pulp was then washed at a pulp consistency of $3.5 \%$ for five minutes using the dewatering and re-circulation procedure described above. A pH optimization of the $\mathrm{Y}$ stage for the reference pulps was carried out, and a $\mathrm{pH}$ between 5.5 and 6.5 was found to be optimal for reaching the highest brightness. The $\mathrm{pH}$ was adjusted with $\mathrm{NaOH}$. In most trials, $0.1 \% \mathrm{Na}_{4}$ EDTA was added together with the dithionite in the bleaching stage. The unbleached pulps were in some cases treated with $0.2 \% \mathrm{Na}_{5}$ DTPA in a $\mathrm{Q}$ stage to reduce the metal content before bleaching. The $\mathrm{Na}_{2} \mathrm{~S}_{2} \mathrm{O}_{4}, \mathrm{Na}_{4}$ EDTA and $\mathrm{Na}_{5}$ DTPA addition levels are given as $100 \%$ active component calculated on bone dry pulp.

\section{Hydrogen peroxide bleaching}

High consistency hydrogen peroxide bleaching was performed at a pulp consistency of $25 \%$ in plastic bags at a temperature of $70^{\circ} \mathrm{C}$. Between 1 and $6 \%$ hydrogen peroxide was used and an alkali optimization was done by varying the sodium hydroxide charge (between 0.2 and $5.3 \%$ ) to reach the highest possible brightness level. The sodium silicate charge was 0.7 times that of the $\mathrm{H}_{2} \mathrm{O}_{2}$ charge. After a retention time of 180 minutes, the pulp 
was cooled to room temperature and diluted to $10 \%$ pulp consistency. After five minutes, the bleached pulp was dewatered and the filtrate re-circulated once to avoid losses of fibres and fine material. The filtrate was collected and used to determine residual hydrogen peroxide, $\mathrm{pH}$ and COD values according to the procedures described below. The bleached pulp was then washed at a pulp consistency of $3.5 \%$ for five minutes using the dewatering and re-circulation procedure described above. The $\mathrm{H}_{2} \mathrm{O}_{2}$ and $\mathrm{NaOH}$ addition levels are given as $100 \%$ active component calculated on bone dry pulp whereas the addition level for sodium silicate is given as commercial product calculated on bone dry pulp. The total alkali charge given in text and figures is calculated according to $E q[1]$.

Total alkali charge $(\%)=$ Sodium hydroxide charge $(\%)$ $+0.156 \times$ Sodium silicate charge $(\%)$

\section{Analyses}

The brightness of the chelated, washed and/or bleached pulps were determined according to ISO standard method 2470. The chemical oxygen demand was determined with a Dr. Lange XION 500 spectrophotometer and according to the method for Dr. Lange Classic COD Cuvette Test. The metal ion content of the wood and pulps was determined after wet combustion with nitric acid using a microwave system with an ICP (inductively coupled plasma) instrument (Iris radial, Thermo ICP s/n 10973). The report limits $(\mathrm{mg} / \mathrm{kg})$ were: $\mathrm{Ca}, 20 ; \mathrm{Cu}, 0.1 ; \mathrm{Fe}, 0.5 ; \mathrm{Mg}$, 20; and Mn, 0.1. Residual hydrogen peroxide was determined by iodometric titration where the liberated iodine was titrated with $0.1 \mathrm{M}$ sodium thiosulphate.

\section{Result and Discussion}

A chemical system based on Fenton's chemistry has been developed and used as an inter-stage treatment for lowering the electrical energy consumption during the refining of Black spruce (Picea mariana) thermomechanical pulp (TMP) (Walter et al. 2009). The chemi- cal system consists of hydrogen peroxide, an activator such as ferrous sulphate and, optionally, an enhancer such as $\mathrm{Na}_{4}$ EDTA, veratryl alcohol (VA) or oxalic acid/sodium oxalate (OA). The acid hydrogen peroxide treatment results in a significant decrease in refining energy consumption of up to $35 \%$ to a freeness value of $100 \mathrm{ml} \mathrm{CSF}$ (cf. Table 1). The energy reduction can be obtained without any substantial change in fibre length, fractional composition of the pulp or tensile strength of the paper. A drawback of the acid hydrogen peroxide treatment is, at present, a reduction in brightness. This paper will therefore examine the bleachability of untreated and chemically treated TMPs. More information about the chemical system can be found in Walter et al. (2009).

\section{Unbleached pulp properties}

The characteristics, including metal ion content and brightness, of the unbleached softwood TMPs used in this investigation are given in Table 1. The metal ion content of the wood raw material is shown in Table 1 for comparison. The iron content increased during processing from $13 \mathrm{mg} / \mathrm{kg}$ for the wood chips to 25 and $64 \mathrm{mg} / \mathrm{kg}$ for the TMP reference (TMP Ref) and the acidic TMP reference (TMP Acid Ref) respectively. This is an effect of the iron content in process waters and the release of iron from process equipment. The acid hydrogen peroxide series with a low addition charge of ferrous sulphate (HP A and HP C series) had an iron content between 160 and 180 $\mathrm{mg} / \mathrm{kg}$ and the trial series with a high addition charge of ferrous sulphate (HP B and HP D series) had an iron content between 290 and $320 \mathrm{mg} / \mathrm{kg}$. These iron contents correlate well with the amount of iron that was introduced via the addition of ferrous activator. Furthermore, there is enrichment in calcium and magnesium content during refining whereas manganese content decreased by $15-35 \%$ depending on the amount of chemicals added (cf. Table 1).

There is a brightness loss connected to the acid hydrogen peroxide treatment (Table 1). The decrease in brightness is to some extent a consequence of the addition of

Table 1. The chemicals used for each refining series, the specific energy consumption (SEC), freeness value, brightness and metal ion content of the starting wood raw material and selected unwashed pulps. Data obtained from (Walter et al. 2009).

\begin{tabular}{|c|c|c|c|c|c|c|c|c|c|c|c|}
\hline \multirow[t]{2}{*}{ Trial series } & \multicolumn{2}{|c|}{$\begin{array}{l}\text { Added chemicals }{ }^{1} \\
\text { [\% of bone dry wood] }\end{array}$} & \multirow[t]{2}{*}{$\begin{array}{c}\text { SEC } \\
{[\mathrm{kWh} / \mathrm{bdt}]}\end{array}$} & \multirow[t]{2}{*}{$\begin{array}{l}\text { Freeness } \\
\text { [ml CSF] }\end{array}$} & \multirow[t]{2}{*}{$\begin{array}{c}\text { Tensile } \\
\text { index }[\mathrm{Nm} / \mathrm{g}]\end{array}$} & \multirow[t]{2}{*}{$\begin{array}{l}\text { Brightness }^{2} \\
\text { [\% ISO] }\end{array}$} & \multicolumn{5}{|c|}{$\begin{array}{c}\text { Metal ion } \\
\text { content }[\mathrm{mg} / \mathrm{kg}]\end{array}$} \\
\hline & $\mathrm{H}_{2} \mathrm{O}_{2}$ & $\mathrm{FeSO}_{4} \times 7 \mathrm{H}_{2} \mathrm{O}$ & & & & & $\mathrm{Ca}$ & $\mathrm{Cu}$ & $\mathrm{Fe}$ & $\mathrm{Mg}$ & $\mathrm{Mn}$ \\
\hline Wood chips & n.a. ${ }^{3}$ & n.a. ${ }^{3}$ & n.a. ${ }^{3}$ & n.a. ${ }^{3}$ & n.a. ${ }^{3}$ & n.a. ${ }^{3}$ & 910 & 0.1 & 13 & 110 & 95 \\
\hline TMP Ref & n.a. ${ }^{3}$ & n.a. ${ }^{3}$ & 2687 & 119 & 42.4 & 56.2 & 1100 & 0.2 & 25 & 250 & 82 \\
\hline TMP Acid Ref ${ }^{4}$ & n.a. ${ }^{3}$ & n.a. ${ }^{3}$ & 2825 & 91 & 54.0 & 55.0 & 1100 & 0.5 & 64 & 250 & 76 \\
\hline HPA & 1.0 & 0.08 & 2250 & 109 & 44.3 & 46.7 & 1100 & $<0.1$ & 170 & 250 & 75 \\
\hline $\mathrm{HPB}$ & 1.1 & 0.15 & 2265 & 75 & 54.2 & 43.1 & 1000 & 0.2 & 320 & 220 & 66 \\
\hline $\mathrm{HPC}$ & 2.2 & 0.08 & 1885 & 116 & 47.1 & 43.3 & 1000 & 0.2 & 160 & 200 & 71 \\
\hline HP D & 2.1 & 0.14 & 1810 & 109 & 47.8 & 42.4 & 960 & $<0.1$ & 310 & 200 & 62 \\
\hline $\mathrm{HPA} 0 \mathrm{x}^{5}$ & 1.0 & 0.08 & 2310 & 98 & 49.8 & 43.9 & 1100 & 0.4 & 180 & 250 & 69 \\
\hline HP A EDTA ${ }^{6}$ & 1.1 & 0.08 & 2173 & 118 & 52.0 & 49.4 & 1100 & $<0.1$ & 160 & 250 & 71 \\
\hline HP D VA ${ }^{7}$ & 2.0 & 0.14 & 1804 & 108 & 48.8 & 43.4 & 1100 & 0.6 & 290 & 220 & 74 \\
\hline
\end{tabular}

${ }^{1}$ Chemicals added to the primary refiner. For details, see Walter et al. (2009)

${ }^{2}$ The brightness values were determined in this study

${ }^{3}$ n.a. $=$ not applicable

${ }^{4} \mathrm{The} \mathrm{pH}$ was adjusted by adding $0.19 \%$ (of bone dry wood) $\mathrm{H}_{2} \mathrm{SO}_{4}$. The $\mathrm{pH}$ (3.8) corresponds to the $\mathrm{pH}$ of the HP trial series

${ }^{5} 0.04 \%$ (of bone dry wood) oxalic acid and $0.04 \%$ (of bone dry wood) sodium oxalate was mixed with the ferrous sulphate

${ }^{6} 0.12 \%$ (of bone dry wood) Na4EDTA was mixed with the ferrous sulphate

${ }^{7} 0.09 \%$ (of bone dry wood) veratryl alcohol (VA) was mixed with the ferrous sulphate 
Table 2. The metal ion content and brightness change after washing or chelating of selected pulps. The metal content before treatment is given in Table 1.

\begin{tabular}{|c|c|c|c|c|c|c|c|c|c|c|c|c|}
\hline Trial series & $\mathrm{Ca}$ & $\mathrm{Cu}$ & $\begin{array}{c}\mathrm{Fe} \\
{[\mathrm{mg} / \mathrm{kg}]}\end{array}$ & $\mathrm{Mg}$ & $\mathrm{Mn}$ & $\begin{array}{l}\Delta \text { Bright. } \\
\text { [\% ISO] }\end{array}$ & $\mathrm{Ca}$ & $\mathrm{Cu}$ & $\begin{array}{c}\mathrm{Fe} \\
{[\mathrm{mg} / \mathrm{kg}]}\end{array}$ & $\mathrm{Mg}$ & $\mathrm{Mn}$ & $\begin{array}{c}\Delta \text { Bright. } \\
\text { [\% ISO] }\end{array}$ \\
\hline & \multicolumn{6}{|c|}{ Water wash, W $\left(70^{\circ} \mathrm{C}\right)$} & \multicolumn{6}{|c|}{ Chelation, $\mathrm{Q}\left(50^{\circ} \mathrm{C}\right)^{1}$} \\
\hline TMP Ref & 900 & 0.4 & 24 & 180 & 58 & +0.7 & 950 & 0.1 & 23 & 200 & 4.6 & -0.1 \\
\hline TMP Acid Ref & 550 & 0.6 & 48 & 90 & 36 & +0.4 & 830 & $<0.1$ & 34 & 160 & 3.9 & +0.3 \\
\hline HPA & 340 & 0.2 & 76 & 40 & 16 & +1.4 & 690 & 0.2 & 71 & 120 & 3.7 & +0.9 \\
\hline HP B & 270 & 0.3 & 120 & 30 & 13 & +2.0 & 640 & $<0.1$ & 100 & 120 & 19 & +1.5 \\
\hline $\mathrm{HPC}$ & 280 & 0.2 & 46 & 20 & 10 & +1.7 & 710 & 0.1 & 37 & 100 & 3.6 & +0.5 \\
\hline HP D & 270 & 0.3 & 80 & 20 & 9.7 & +2.3 & 640 & $<0.1$ & 68 & 90 & 3.1 & +1.1 \\
\hline HPA Ox & 350 & 0.3 & 59 & 40 & 14 & +1.4 & 800 & $<0.1$ & 53 & 130 & 5.4 & +1.2 \\
\hline HP A EDTA & 340 & 0.2 & 50 & 40 & 17 & +1.3 & 700 & 0.1 & 41 & 120 & 3.2 & +0.8 \\
\hline HP D VA & 270 & 0.3 & 57 & 20 & 9.7 & +1.0 & 720 & $<0.1$ & 56 & 100 & 18 & -0.1 \\
\hline \multicolumn{8}{|c|}{ Acidic water wash, $\mathrm{W}_{\mathrm{A}}\left(50^{\circ} \mathrm{C}, \mathrm{pH} 2.3\right)$} & \multicolumn{5}{|c|}{ Reducing agent assisted chelation, $Q_{y}\left(50^{\circ} \mathrm{C}\right)$} \\
\hline TMP Ref & n.a. ${ }^{2}$ & n.a. ${ }^{2}$ & n.a. ${ }^{2}$ & n.a. ${ }^{2}$ & n.a. ${ }^{2}$ & n.a. ${ }^{2}$ & 930 & 0.1 & 12 & 190 & 1.5 & +4.7 \\
\hline HP A & 100 & $<0.1$ & 62 & $<20$ & 5.2 & +0.6 & 750 & $<0.1$ & 20 & 130 & 4.8 & +5.0 \\
\hline HP A EDTA & 100 & $<0.1$ & 32 & $<20$ & 4.6 & +0.1 & n.a. ${ }^{2}$ & n.a. ${ }^{2}$ & n.a. ${ }^{2}$ & n.a. ${ }^{2}$ & n.a. ${ }^{2}$ & n.a. ${ }^{2}$ \\
\hline
\end{tabular}

${ }^{1} 0.2 \% \mathrm{Na}_{5} \mathrm{DTPA}$ was used for all trial series except for HP D where $0.4 \% \mathrm{Na}_{5} \mathrm{DTPA}$ was used

${ }^{2}$ Not analysed

ferrous sulphate, which increases the light absorption coefficient (Walter et al. 2009). The added ferrous activator charges were higher than necessary for the amount of hydrogen peroxide used in the pilot trial and the discoloration associated with the treatment should therefore be reduced when the system is optimized.

\section{Washing and chelating}

Washing and chelating experiments were performed in order to examine whether it was possible to reduce the iron content of the pulps and thereby regain some of the brightness that was lost during the chemical treatment. Furthermore, removal of metals from pulps is an essential process step in bleaching processes that are based on oxygen-containing chemicals. It is well known that transition metals such as manganese, iron and copper catalyze the decomposition of hydrogen peroxide whereas other metals (e.g., magnesium and calcium) have a stabilizing effect (Dick, Andrews 1965; Colodette, Dence 1989; Abbot et al. 1992; Froass et al. 1993). Transition metals (especially iron and copper) can also cause decomposition of dithionite (Ganguli 1980; Rieber 2000).

A thorough water wash $(\mathrm{W})$ at $70^{\circ} \mathrm{C}$ could reduce the metal ion content of chemically treated pulps considerably, though brightness was only raised by a maximum of two ISO units (Table 2), i.e., the brightness lost during acid hydrogen peroxide treatment could only marginally be regained by washing solely with water. Between 50 and $80 \%$ of the added iron (cf. Fig 1 a) could, however, be removed by a warm water wash and other metals, such as manganese, could also be reduced by washing (cf. Tables 1 and 2). For example, about 80 to $90 \%$ of the manganese in the acid hydrogen peroxide-treated pulps could be washed out compared to only about $30 \%$ and $60 \%$ from the reference pulps, TMP Ref and TMP Acid Ref respectively (cf. Fig 1 b). An acidic water wash $\left(\mathrm{W}_{\mathrm{A}}\right)$ at $\mathrm{pH} 2.3$ could reduce the manganese content by as much as 90 to $95 \%$ for the HP A and HP A EDTA trial series, i.e., almost as effective as treating the pulp with $\mathrm{Na}_{5}$ DTPA in a chelating (Q) stage (Table 2). $\mathrm{A} \mathrm{W}_{\mathrm{A}}$ proce-
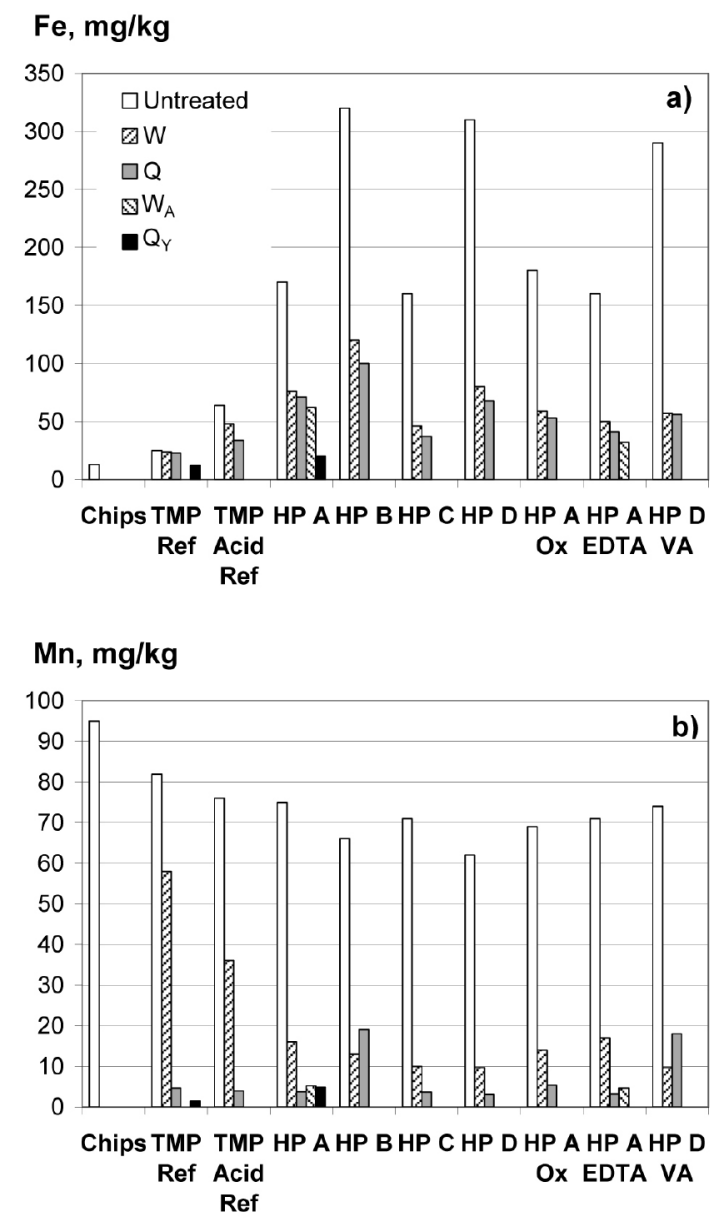

Figs 1a-b. Iron and manganese contents of references and acid hydrogen peroxide-treated pulps before and after different washing and chelation treatments. The iron and manganese content of the wood raw material (chips) is included for comparison. The legends are given in Fig $1 a$ and the abbreviations used are explained in Tables 1-2.

dure could also reduce the iron content somewhat more compared to washing with water or chelating with $\mathrm{Na}_{5}$ DTPA (Fig la).

It has previously been shown that a treatment with a chelant, in combination with a reducing agent, is more efficient in removing transition metal ions from thermo- 
mechanical pulps than chelation alone (Ni et al. 1998b). A reducing agent-assisted chelating $\left(Q_{Y}\right)$ stage with sodium dithionite was the most effective of all evaluated methods for reducing iron content (Table 2). The iron content of the acid hydrogen peroxide-treated pulp, HP $\mathrm{A}$, after a $\mathrm{Q}_{\mathrm{Y}}$ stage is similar to the iron content of the conventional chelated TMP Ref pulp. During the $\mathrm{Q}_{\mathrm{Y}}$ stage, the brightness of the TMP ref and HP A pulps increases by about five ISO brightness units, mainly due to the bleaching effect of the dithionite. The discoloration of the treated pulps (cf. Table 1) is thus not only caused by a higher iron content in the pulp but the type of iron compound and/or other coloured compounds connected with the acid hydrogen peroxide treatment has an effect.

The washing or chelating treatments also reduce other metals like calcium and magnesium. The chemically treated pulps contain 150 to $310 \mathrm{mg} / \mathrm{kg}$ less calcium and 70 to $110 \mathrm{mg} / \mathrm{kg}$ less magnesium than the TMP Ref series after a chelating stage (Table 2), which may have a negative effect on the subsequent bleaching (Froass et al. 1993; Lindholm 1999). The addition of magnesium before or during the bleaching stage may therefore be advantageous.

A chelating stage with $\mathrm{Na}_{5} \mathrm{DTPA}$ was used to reach low manganese (about $4 \mathrm{mg} / \mathrm{kg}$ ) levels prior to hydrogen peroxide bleaching. For pulps with a high addition of ferrous sulphate (HP B and HP D series), the added $0.2 \%$ $\mathrm{Na}_{5}$ DTPA was not sufficient. For HP D, 0.4\% $\mathrm{Na}_{5} \mathrm{DTPA}$ was used to reach a manganese content of about $3 \mathrm{mg} / \mathrm{kg}$ and that amount of chelating agent would probably be needed for the HP B and HP D VA series as well (cf. Table 2).

\section{Dithionite bleaching}

Medium consistency dithionite bleaching was performed at a temperature of $60^{\circ} \mathrm{C}$ using $1 \% \mathrm{Na}_{2} \mathrm{~S}_{2} \mathrm{O}_{4}$. The brightness gain after bleaching with dithionite alone was about 7 ISO brightness units for both the TMP Ref and HP A EDTA series (cf. Fig 2). The addition of $0.1 \% \mathrm{Na}_{4}$ EDTA to the bleaching solution in the dithionite stage increased the brightness by one additional brightness unit for the same two pulps, i.e., a total brightness gain of about 8 ISO brightness units was achieved. It was also beneficial if the pulps were chelated with $0.2 \% \mathrm{Na}_{5} \mathrm{DTPA}$ before bleaching, and with this sequence (Q Y), the TMP Ref and HP A EDTA series gained a maximum of 8.5 ISO brightness units.

In general, the reference pulps and the acid hydrogen peroxide-treated pulps had about the same maximum brightness increase in the dithionite bleaching stage and consequently the brightness gap between the unbleached references and the acid hydrogen peroxide-treated pulps could not be completely eliminated by reductive bleaching. The brightness could, however, be recovered to the unbleached level of the references for the trial series HP A and HP A EDTA. The reference TMP series (TMP Ref) reached a brightness of $65.0 \%$ ISO using $1 \%$ $\mathrm{Na}_{2} \mathrm{~S}_{2} \mathrm{O}_{4}$ whereas HP A EDTA only reached $58.5 \%$ ISO.

The unbleached and non-chelated acid hydrogen peroxide-treated pulps had 3 to $10 \mathrm{~kg} / \mathrm{t}$ more COD in the

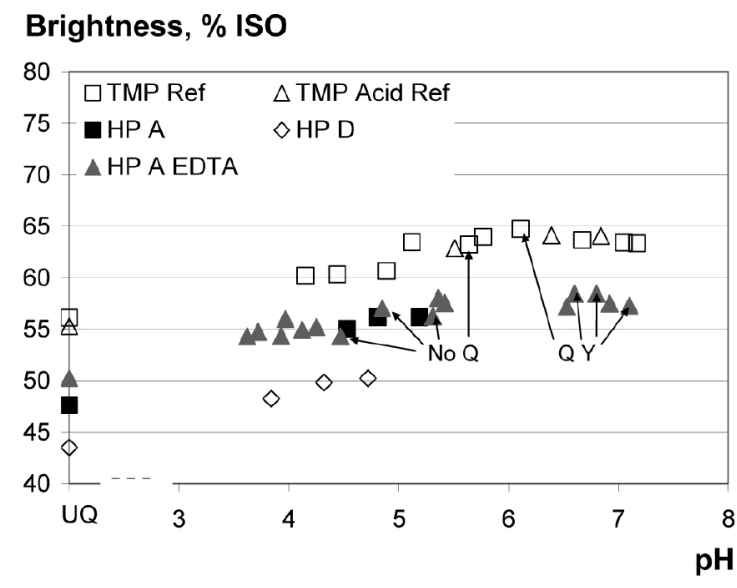

Fig 2. The ISO brightness of unbleached and chelated (UQ) and dithionite (1\% addition) bleached pulps. 0.2\% $\mathrm{Na}_{5}$ DTPA was added before bleaching (marked $\mathrm{Q}$ $Y$ in the figure), $0.1 \% \mathrm{Na}_{4}$ EDTA was added to the bleaching solution (unmarked) or no chelating agent was used before or during bleaching (marked No Q).

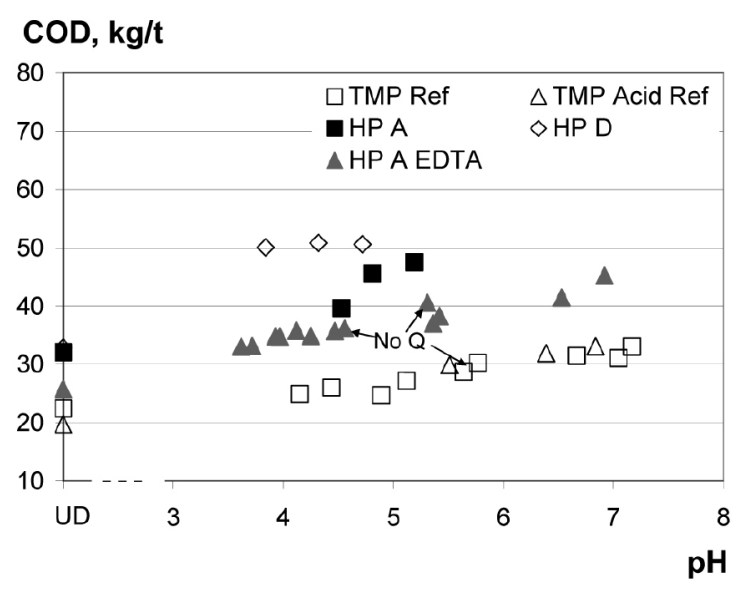

Fig 3. The chemical oxygen demand (COD) of unbleached and dewatered (UD) and dithionite (1\% addition) bleached pulps. Some of the bleaching trials were performed without any chelating agent present (marked No $Q$ in the figure). In the rest of the trials, $0.1 \% \mathrm{Na}_{4}$ EDTA was added to the bleaching solution.

water phase than the TMP Ref pulp before entering the bleaching stage. The dithionite bleaching, with and without $\mathrm{Na}_{4}$ EDTA included, did further increase the difference in COD to 6 to $20 \mathrm{~kg} / \mathrm{t}$ (Fig 3). About half of the increase was a consequence of the higher alkali charge to reach the optimal $\mathrm{pH}$ for bleaching. Among the chemically treated pulps, the HP A EDTA showed the lowest COD values both before and after reductive bleaching.

\section{Hydrogen peroxide bleaching}

High consistency hydrogen peroxide bleaching was performed at a pulp consistency of $25 \%$ and a temperature of $70^{\circ} \mathrm{C}$. The hydrogen peroxide charge was varied between 1-6\% and alkali-optimized to reach the highest brightness. Fig 4 presents the ISO brightness values obtained at the optimum total alkali charges. The discoloration caused by the acid hydrogen peroxide treatment is reduced after the oxidative bleaching but not completely eliminated. The difference between the HP A EDTA pulp and the TMP Ref pulp was 6 brightness units before bleaching but lowered to about 2.5 units after bleaching with $6 \%$ hydrogen peroxide. A hydrogen peroxide charge of about $4.8 \%$ was needed to reach an 
Brightness, \% ISO

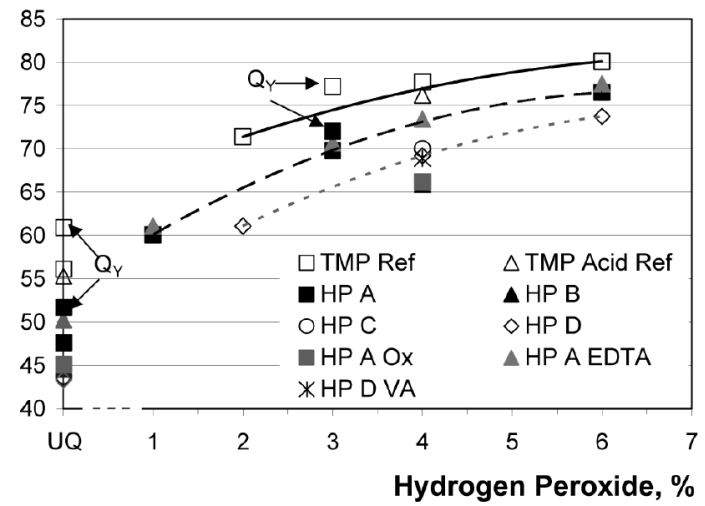

Fig 4. The ISO brightness as a function of hydrogen peroxide charge in the bleaching stage at optimum alkali charge for untreated and acid hydrogen peroxidetreated pulps. The unbleached chelated pulp brightness can be found on the $Y$ axis, denoted UQ. Trend lines are drawn for the TMP Ref, HP A and HP D pulps. Reducing agent-assisted chelated pulps are denoted $Q_{\mathrm{r}}$.

ISO brightness of $75 \%$ for the HP A pulp whereas the corresponding hydrogen peroxide charge was about $3.2 \%$ for the reference TMP (TMP Ref, Fig 4). The manganese content of the HP B and HP D VA series was high after the $\mathrm{Q}$ stage (about $20 \mathrm{mg} / \mathrm{kg}$, see Table 2) and the obtained brightness after hydrogen peroxide bleaching would have been higher if the manganese content had been reduced more in the chelating stage. It can further be concluded that oxidative bleaching of the chemically treated pulps using $1 \%$ hydrogen peroxide will give higher brightness gains compared to reductive bleaching with $1 \%$ dithionite (cf. Figs 2 and 4).

Hydrogen peroxide bleaching was also performed after a reducing agent-assisted chelating $\left(\mathrm{Q}_{\mathrm{Y}}\right)$ stage with $0.5 \%$ dithionite. The $\mathrm{Q}_{\mathrm{Y}}$ treatment alone increased the brightness by about 5 ISO units compared to conventional Q treatment (see y-axis, Fig 4). The positive effect with a $\mathrm{Q}_{\mathrm{Y}}$ treatment remains to a large extent after bleaching; brightness improvement compared to $\mathrm{Q} P$ is 2-3 ISO units with the $\mathrm{Q}_{\mathrm{Y}} \mathrm{P}$ sequence when $3 \%$ hydrogen peroxide is charged (Fig 4). Both the TMP Ref pulp and the HP A pulp have the same brightness development after a $Q_{Y}$ stage. By exchanging the $Q$ stage for a $Q_{Y}$ stage, the hydrogen peroxide charge in the subsequent bleaching stage can be reduced to approximately $3.8 \%$ and the HP A pulp can still reach an ISO brightness of $75 \%$. The corresponding hydrogen peroxide charge for the untreated TMP reference was about $2.5 \%$ for the $\mathrm{Q}_{\mathrm{Y}} \mathrm{P}$ sequence. The additional cost of chemicals needed during bleaching have to be compared with the cost savings due to energy reduction during refining. The profitability of the concept is, in the end, mill specific.

The amount of dissolved substances (measured as COD) after a thorough hot water wash $\left(\mathrm{W}, 70^{\circ} \mathrm{C}\right)$ was of the same magnitude as the COD measured in the water phase of the refined pulps together with the COD removed during a $\mathrm{Q}$ stage (Fig 5). Five of the pulps were bleached and the COD carry-over into the hydrogen peroxide bleaching was between 1 and $4 \mathrm{~kg} / \mathrm{t}$. The acid hydrogen peroxide system increased the amount of organic compounds that was released both before and after alkaline hydrogen peroxide bleaching. More alkali was needed in the oxidative bleaching

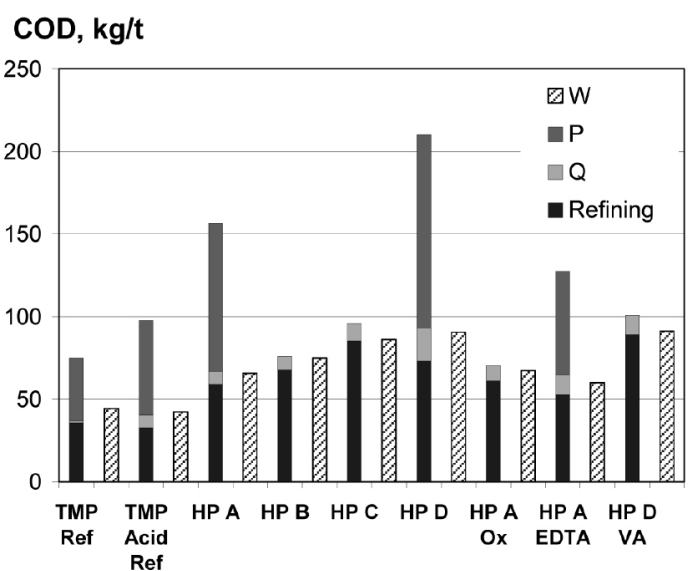

Fig 5. The chemical oxygen demand (COD) produced at different stages (refining, $\mathrm{Q}=$ chelation, $\mathrm{P}=$ hydrogen peroxide bleaching and $\mathrm{W}=$ hot wash) when processing untreated and acid hydrogen peroxide-treated pulps. The five hydrogen peroxide bleached pulps had a brightness of $74-75 \%$ ISO.

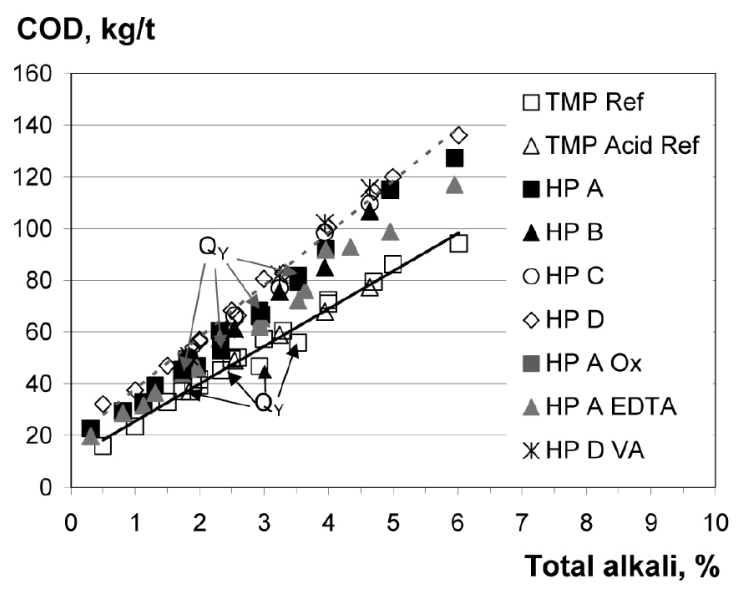

Fig 6. The chemical oxygen demand (COD) produced during hydrogen peroxide bleaching as a function of total alkali charge in the bleaching stage. Trend lines are drawn for the TMP Ref and HP D pulps.

stage in order to obtain maximum brightness at a given hydrogen peroxide charge. The increased charge of alkali can to a large extent explain the increase in COD after bleaching of the chemically treated pulps, regardless of the type of chelating pre-treatment $\left(\mathrm{Q}\right.$ or $\mathrm{Q}_{\mathrm{Y}}$ ) applied (Fig 6). The enhancer $\mathrm{Na}_{4}$ EDTA, which was added during refining, had a beneficial effect and the released amount of COD for the HP A EDTA series was of the same magnitude as for the TMP Acid Ref series during hydrogen peroxide bleaching (Fig 5).

It is evident that the amount of dissolved substances will decrease during hydrogen peroxide bleaching if the brightness loss, which occurs as a consequence of the acid hydrogen peroxide treatment, can be reduced. Further work aiming to optimize the chemical charges and reaction conditions of the developed chemical system for lowering the electrical energy consumption with regard to yield loss and discoloration is therefore ongoing.

\section{Conclusions}

This paper describes how the brightness of the acid hydrogen peroxide-treated Black spruce (Picea mariana) thermomechanical pulps (TMPs) can be increased by 
washing, chelating and bleaching the pulps. The amount of iron in a chemically treated pulp can be reduced to the level of an untreated pulp by a reducing agent-assisted chelating stage, without substantially lowering the brightness gap between the pulps. The brightness decrease of the treated pulps is thus not only caused by higher iron content in the pulp but is also dependent on the type of iron compound and/or other coloured compounds connected with the acid hydrogen peroxide treatment.

The overall results indicate that oxidative bleaching with hydrogen peroxide is more effective than reductive bleaching with dithionite. Depending on pre-treatment strategy, it is possible to reach a brightness of $75 \%$ ISO for the chemically treated pulp by using 3.8-4.8\% hydrogen peroxide. The analogous hydrogen peroxide charge for the untreated TMP reference is $2.5-3.2 \%$.

The amount of ferrous sulphate added in the energy reduction system influences the resulting unbleached pulp brightness. The level of added ferrous sulphate was higher than necessary when producing the low energy pulps evaluated in this study and the possibility to reduce the discoloration and thereby further improve brightness and bleachability should be considerable when the acid hydrogen peroxide system is optimized.

\section{Acknowledgements}

Financial support from the Knowledge Foundation is gratefully acknowledged. The authors thank Professor Per Engstrand, Mid Sweden University, Sundsvall, Sweden for valuable discussions.

\section{Literature}

Abbot, J., Brown, D.G., Hobbs, G.C., Jewell, I.J. and Wright, P.J. (1992): The influence of manganese and magnesium on alkaline peroxide bleaching of radiate pine thermomechanical pulp, Appita J. 45(2), 109-112, 120.

Agarwal, U.P. and Akhtar, M. (2000): Understanding fungus-induced brightness loss of biomechanical pulps, Pulping/Process and Product Quality Conf., Boston, MA, USA, November 5-8, TAPPI, Atlanta, GA, USA, 12pp.

Akamatsu, I., Yoshihara, K., Kamishima, H. and Fujii, T. (1984): Influence of white-rot fungi on poplar chips and thermo-mechanical pulping of fungi-treated chips (in Japanese), Mokuzai Gakkaishi, 30(8), 697-702.

Akhtar, M., Attridge, M.C., Myers, G.C. and Blanchette, R.A. (1993): Biomechanical pulping of loblolly pine chips with selected white-rot fungi, Holzforschung, 47(1), 36-40.

Akhtar, M., Blanchette, R.A., Myers, G. and Kirk, T.K. (1998): An overview of biomechanical pulping research, In: Young, R.A. and Akhtar, M. (ed.), Environmentally Friendly Technologies for the Pulp and Paper Industry, John Wiley and Sons, Inc., New York, NY, USA, pp. 309-340.

Ali (Viforr), S. and Salmen, L. (2005): From wood shavings to mechanical pulp - A new raw material?, Nord. Pulp Paper Res. J. 20(4), 418-422.

Colodette, J.L. and Dence, CW. (1989): Factors affecting hydrogen peroxide stability in the brightening of mechanical and chemi-mechanical pulps, Part IV: The effect of transition metals in Norway spruce TMP on hydrogen peroxide stability, J. Pulp Paper Sci. 15(3), J79-J83.

Dick, R.H. and Andrews, D.H. (1965): The bleaching of groundwood pulp with peroxide. The influence of certain metals on bleach response, Pulp Paper Mag. Can. 62(3), T201-T208.

Francis, B., Towers, M. and Browne, T. (2006): Benchmarking energy use in pulp and paper operations, 92nd Annual meeting of the Pulp and Paper Technical Association of Canada, Montreal, QC, Canada, February 7-9, PAPTAC, Montreal, QC, Canada, Book A, pp. A55-A61.

Froass, W.C., Omori, S., Francis, C. and Dence, C. W. (1993): Effects of recycling peroxide liquor on brightness of mechanical pulp, Tappi J. 76(11), 111-119. Ganguli, K. K. (1980): Sodium hydrosulfite bleaching of TMP improved with metal chelants, Pulp and Paper, 54(10), 108-112.

Höglund, H., Bäck, R., Falk, B. and Jackson, M. (1997): Thermopulp - A new energy-efficient mechanical pulping process, Pulp Paper Can. 98(6), T215-T222. Jackson, M. and Wild, N.W. (1999): Mechanical pulp mills, In: Williamson, P. N. (ed.), Energy Cost Reduction in the Pulp and Paper Industry, The Pulp and Paper Technical Association of Canada, Montreal, Quebec, Canada, pp. 97-118.

Janson, J. and Forsskåhl, I. (1989): Color changes in lignin-rich pulps on irradiation by light, Nord. Pulp Paper Res. J. 4(3), 197-205.

Lindholm, C.-A. (1999): Bleaching, In: Sundholm, J. (ed.), Mechanical Pulping, Fapet Oy, Helsinki, Finland, pp. 313-343.

Luoma, M., McGregor, C. and Freeman, W. L. (2004): Advanced retention and drainage technology offers performance and stability improvements and operational cost savings, Paper Technology, 45(9), 22-26.

Ni, Y., Li, Z. and van Heiningen, A.RP. (1997): Minimization of the brightness loss due to metal ions in process water for bleached mechanical pulps, 83rd Annual Meeting, Technical Section CPPA, Montreal, Quebec, Canada, January 30 31, CPPA, Montreal, Quebec, Canada, Vol. B, pp. B43-B49.

Ni, Y., Ghosh, A., Li, C., Heitner, C. and McGarry, P. (1998a): Photostabilization of bleached mechanical pulps with DTPA treatment, J. Pulp Paper Sci. 24(8), 259-263. Ni, Y., Li, Z., Jiang, Q., Court, G. and Burtt, M. (1998b): Improved transition metal removal in a reducing agent-assisted chelation stage: a laboratory study, Pulp Paper Can. 99(8), 77-79.

Ni, Y., Ng, A. and Mosher, M. (1999): A Model compound study: The formation of colored metallic extractive complexes and their effect on brightness of TMP pulp, J. Wood Chem. Technol. 19(3), 213-223.

Norgren, S., Höglund, H. and Bäck, R. (2004): Irreversible long fibre collapse at high temperature TMP reject refining - initial studies, Pulp Paper Can. 105(7), 47-51. Ohlsson, L. and Federer, R. (2002): Efficient use of fluorescent whitening agents and shading colourants in the production of white paper and board, Tappi J. (Nov), 25-28.

Peart, C. and Ni, Y. (2001): UV-Vis spectra of lignin model compounds in the presence of metal ions and chelants, J. Wood Chem. Technol. 21(2), 113-125.

Rieber, W. (2000): The role of silicates in reductive bleaching processes, 9th PTS-CTP Deinking Symp., Munich, Germany, May 9-11, Papiertechnische Stiftung, Munich, Germany, 14pp.

Setliff, E.C., Marton, R., Granzow, S.G. and Eriksson, K.L. (1990): Biomechanical pulping with white-rot fungi, Tappi J. 73(8), 141-147.

Viljakainen, E. (2006): High-quality mechanical pulps in paper and board manufacture, Int. Papwirtsch. (9), 47-51.

Walter, K., Paulsson, M. and Wackerberg, E. (2009): Energy efficient refining of Black spruce TMP by using acid hydrogen peroxide: Part 1. A pilot plant study, Nord. Pulp Paper Res. J. 24(3), 255-265.

Manuscript received February 13, 2009 Accepted March 25, 2009 